\title{
Patterns of fruit and vegetable availability and price competitiveness across four seasons are different in local food outlets and supermarkets
}

\author{
Natalie Valpiani ${ }^{1} * *$, Parke Wilde ${ }^{1}$, Beatrice Rogers ${ }^{1}$ and Hayden Stewart ${ }^{2} \uparrow$ \\ ${ }^{1}$ Gerald J. and Dorothy R. Friedman School of Nutrition Science and Policy, 150 Harrison Avenue, Boston, MA \\ 02111, USA: ${ }^{2}$ Economic Research Service, US Department of Agriculture, Washington, DC, USA
}

Submitted 27 January 2014: Final revision received 8 February 2015: Accepted 19 February 2015: First published online 21 April 2015

\begin{abstract}
Objective: To explore the effect of seasonality on fruit and vegetable availability and prices across three outlet types (farmers' markets, roadside stands and conventional supermarkets).

Design: Cross-sectional survey of geographically clustered supermarkets, farmers' markets and roadside stands. Enumerators recorded the availability and lowest price for eleven fruits and eighteen vegetables in each season of 2011.

Setting: Price data were collected at retail outlets located in central and eastern North Carolina.

Subjects: The sample consisted of thirty-three supermarkets, thirty-four farmers' markets and twenty-three roadside stands.

Results: Outside the local harvest season, the availability of many fruits and vegetables was substantially lower at farmers' markets and roadside stands compared with supermarkets. Given sufficient availability, some items were significantly cheaper $(P<0.05)$ at direct retail outlets in the peak season (e.g. cantaloupe cost $36.0 \%$ less at roadside stands than supermarkets), while others were significantly more expensive (e.g. carrots cost $137.9 \%$ more at farmers' markets than supermarkets). Although small samples limited statistical power in many non-peak comparisons, these results also showed some differences by item: two-thirds of fruits were cheaper at one or both direct outlets in the spring and autumn, whereas five of eighteen vegetables cost more at direct retail year-round.

Conclusions: Commonly consumed fruits and vegetables were more widely available at supermarkets in central and eastern North Carolina than at direct retail outlets, in each season. Contingent on item availability, price competitiveness of the direct retail outlets varied by fruit and vegetable. For many items, the outlets compete on price in more than one season.
\end{abstract}

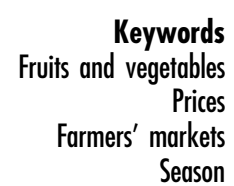

Despite the documented health benefits of consuming sufficient fruit and vegetables, such as reduced risk of stroke, CHD and some cancers, most Americans fall short of meeting the daily intake recommendations outlined in the 2010 Dietary Guidelines for Americans ${ }^{(1-4)}$. Fewer than one-third of US adults consume at least two servings of fruit or three servings of vegetables each day ${ }^{(5)}$.

Research has explored the effect of both produce availability and price on fruit and vegetable consumption. The presence of an additional supermarket per census tract, shorter distances to the nearest supermarket and increased

$\dagger$ Any opinions, findings, recommendations, or conclusions are those of the authors and do not necessarily reflect the views of the Economic Research Service, US Department of Agriculture. shelf space devoted to fruits and vegetables have each been associated with increased intake ${ }^{(6-8)}$. Additional studies debate the extent to which price affects intake ${ }^{(9-13)}$. Consumer perceptions alone regarding availability and price may also influence fruit and vegetable intake ${ }^{(14,15)}$.

Concurrent attention to the effects of the food environment and the rapid expansion of direct farmer-to-consumer marketing has prompted interest in the potential of 'local food' outlets, characterized by direct farmer-to-consumer retail, to improve produce availability and affordability ${ }^{(16)}$. Two refereed studies, one conducted in California and the other in North Carolina, suggest that farmers' markets offer lower prices than supermarkets for most items ${ }^{(17,18)}$. Other literature reports fewer significant differences, suggesting that prices are similar across outlets ${ }^{(19,20)}$. One of these studies examined 
prices in the non-peak season, and then at just one market, while most other previous studies focus instead just on the peak season. One recent Report to Congress by the US Department of Agriculture (USDA) uses nationally representative Nielsen Homescan Panel Data in all seasons to compare produce prices in supercentres, grocery stores and direct-to-consumer outlets, a category that includes farmers' markets but that is not limited strictly to local foods ${ }^{(21)}$.

Whether or not seasonality impacts these price comparisons is a question relevant to the promotion of direct retail as a means to boost produce intake, especially among lowincome consumers. There are several reasons for which we hypothesized that seasonality does impact these comparisons. First, the existence of seasonal variation in fresh fruit and vegetable prices has been documented in wholesale and traditional retail markets ${ }^{(22-25)}$. Second, past research suggests both that supermarkets seek to dampen price volatility and that a large fraction of the retail price at supermarkets covers costs that do not fluctuate seasonally such as storage, transportation, packaging and marketing ${ }^{(26)}$. In contrast, farmer-toconsumer direct marketing has fewer of these intermediate, relatively fixed costs in the chain between farm and fork ${ }^{(27)}$. Farmers lacking cold storage facilities may be willing to offer discounts to move supply at the peak of the local harvest season. Finally, rather than downplaying price volatility, the possibility of seasonal discounts has been used to promote local foods ${ }^{(28,29)}$. Given these considerations, perhaps the competitive prices noted in previous studies are unique to the summer season and result from greater price volatility at direct retail outlets than at supermarkets.

Building on an analysis of weighted mean prices for produce in just one season ${ }^{(30)}$, the present study compares the availability and price of commonly consumed fruit and vegetables at three outlet types, across the four seasons of the year, using data collected in central and eastern North Carolina. Three questions are addressed:

1. Do the outlet types experience similar seasonal patterns in item availability?

2. During their local harvest season, are fruits and vegetables least expensive at direct retail outlets?

3. Are direct retail outlets and traditional supermarkets price competitive in all seasons?

The original intention had been to draw an overall conclusion about the price competitiveness of direct retail outlets in different seasons. It turns out that the answer to each of the three main research questions differed across the fruit and vegetable items, so the present study discusses key results separately by item.

\section{Experimental methods}

\section{Study design}

In order to study the effect of outlet type on prices across seasons, thirty-four sites, each consisting of three outlet types, were sampled and visited by enumerators in each of the four seasons. The study methods are summarized below, with further detail available elsewhere ${ }^{(30)}$.

\section{Outlet selection}

The sampling plan was designed to select a sample representative of all farmers' markets operating in central and eastern North Carolina. First, probability-proportionalto-size sampling, based on the number of food vendors at a market, was used to select thirty-four farmers' markets from a sampling frame of all markets in the area. Next, a supermarket was randomly sampled from those located within a 5-mile $(8.05 \mathrm{~km})$ drive of the farmers' market. With this sampling design, the study could estimate the mean difference between direct retail outlet prices and supermarket prices in this region of North Carolina, but it could not produce separate estimates of the differential between direct retail and supermarket prices in each local market. An outlet was considered a supermarket if it had annual sales of at least \$US 2 million and at least five main departments (fresh meat and poultry, produce, dairy, dry and packaged goods, and frozen foods) consistent with the definition of a supermarket used by the USDA. Superstores, which in addition to foods carry a variety of non-food goods, were excluded. At the time of the study, supermarkets captured $64 \cdot 1 \%$ of Americans' food-at-home spending ${ }^{(30)}$. Although superstores have gained an increasing share of consumer food-at-home spending over the past few decades, traditional supermarkets captured the majority of food-at-home sales at the time the study was designed $^{(31)}$. Finally, a roadside stand was randomly sampled from a frame of all stands within a 5-mile drive of the farmers' market. If none existed within 5 miles, a stand was drawn from within a 10 -mile $(16 \cdot 1 \mathrm{~km})$ radius. Roadside stands were available for twenty-three of the sites.

We sought a sample size sufficient to examine fruit and vegetable prices by outlet type, season and produce form (e.g. fresh $v$. frozen). When the study was designed, the literature contained no data on seasonal price changes at direct retail outlets and very little by way of price comparisons between supermarkets and farmers' markets ${ }^{(17,19)}$. In prior research ${ }^{(32)}$, the average price difference between two forms of produce ranged from \$US 0.11 to $\$$ US 0.31 per serving. Thus, we estimated the sample size required to detect a \$US $0 \cdot 10$ difference in price per serving between form combinations (fresh $v$. canned, canned $v$. frozen, etc.), with $\alpha=0.05$ and $\beta=0.8$. These estimated requirements ranged from twelve to fortysix outlets; in only two of eight cases did the sample size exceed twenty-eight. Given budgetary and logistical constraints, a target sample size of thirty, augmented to thirtyfour to account for refusal to participate, was selected. The sample for the present study contained twice the number of farmers' markets as the few previously published studies regarding price differences (per weight or per item) by outlet type ${ }^{(17,19)}$. In the data collected, power and 
sample size turned out to vary greatly by item and season, as will be noted further in the Results section. Of course, there were few observations for highly seasonal items at farmers' markets and roadside stands observed in the off season.

\section{Produce selection}

The fruits and vegetables studied were selected based on Americans' produce intake. Twenty-four hour dietary recall data collected by the nationally representative National Health and Nutrition Examination Survey (NHANES) were used to calculate the grams of fruits and vegetables consumed by Americans aged 2 years and older $^{(33)}$. The contribution of each item to total fruit or total vegetable intake, as well as to the intake of different produce forms (fresh, canned, frozen and juice), was calculated and the items ranked accordingly.

This ranked list of fruits and vegetables was then consolidated to be as short as possible, while still representing close to $80 \%$ of total fruit and total vegetable consumption when considering all forms. Some items that contributed smaller amounts to total intake, such as blueberries, were included due to their importance in North Carolina direct retail. Others, like pineapple, were included because they proved important to a non-fresh form (supermarkets only, separate analysis). Eleven fruits and eighteen vegetables were selected.

\section{Seasonality}

Enumerators collected prices at each outlet once during each of the four seasons of 2011. The data collection periods were designed to be approximately evenly distributed over the year while capturing seasonal changes in North Carolina food production and availability. Each period was kept as short as possible to reduce the potential for intra-season price variation. Enumerators collected data in the following periods:

1. Winter: 18 January-12 February 2011.

2. Spring: 30 April-28 May 2011.

3. Summer: 16 July-7 August 2011.

4. Autumn: 1 October-23 October 2011.

\section{Data collection procedures}

At each outlet, enumerators collected data about the availability, price, the location of production and the methods of production (organic or conventional) for each fruit or vegetable. Data were collected about the variety with the lowest unit price. Prices were recorded per pound (lb) or per item, as displayed by the vendor. For those sold per item (e.g. cantaloupe) enumerators recorded the weight of three items. These weights were averaged during analysis to account for the variation in the size of fresh produce items. Sales available by store loyalty card were included, while sales requiring a coupon were not.

If multiple vendors sold produce at a farmers' market, enumerators sampled one vendor using a random number table. They then collected data for all the items available for sale by that vendor before repeating this procedure until they had completed as many items as possible. The instruments and protocol for the study were determined exempt from review by the Tufts University Institutional Review Board at Medford.

\section{Analysis}

Data analysis was conducted in the statistical software package Stata IC version 10.0. Supermarket prices were multiplied by the $2 \%$ local food tax so that prices represented what consumers actually paid for each item. Prices were converted from $\$ \mathrm{US} / \mathrm{lb}$ to $\$ \mathrm{US} /$ cup equivalent as defined by the USDA MyPyramid Food Guidance System ${ }^{(31)}$. The number of edible cup equivalents in each item in its 'as purchased' form was calculated as follows:

1. The weight of the observed item was converted from pounds to grams.

2. For fresh items, the weight of the portion not typically consumed (e.g. peel, seeds, etc.) was subtracted. This weight was determined from the USDA National Nutrient Database for Standard Reference, Release $18^{(34)}$.

3. The number of cup equivalents per 100 edible grams of the item was calculated using the USDA MyPyramid Equivalents Database, 2.0.

Descriptive statistics were calculated to characterize the sample of outlets and to describe the pattern of availability of each fruit and vegetable item across the four seasons, by outlet type. Next, the effect of outlet type on price per cup equivalent was examined for each produce item, in each season. Within each season, the mean price per cup equivalent for an item at farmers' markets was compared with the price at supermarkets and roadside stands by employing one-way ANOVA models with Bonferroni corrections for multiple group comparisons. Additionally, weighted means were calculated across all fruits and vegetables. The price of each item was weighted by its contribution to total fresh fruit and vegetable intake, as reported in NHANES. Results are considered significant if the associated $P$ value is less than 0.05 . A significant $P$ value indicates that the probability of observing a given difference in mean price between two outlet types, if in reality no price difference existed, is less than $0 \cdot 05$. It thus suggests that the observed mean difference in the sample is due to an actual price difference in the population and not due to sampling variation.

Also of interest was whether the magnitude of price change observed from one season to the next, for each item, was consistently larger for one of the three outlet types. To compare seasonal price changes, ANOVA was used to model the price per cup equivalent of an item on season, outlet type and their interaction. A series of individual $F$ tests was then conducted to test the null hypotheses that the difference in season-to-season change 
at one outlet equalled the change at another outlet type. These tests were conducted for changes from winter to spring, spring to summer, summer to autumn, and autumn to winter, and repeated for each fruit and vegetable.

\section{Results}

\section{Question 1: Seasonal item availability}

The first research question is whether supermarkets, farmers' markets and roadside stands experience similar seasonal patterns in item availability. Most farmers' markets and roadside stands were open only in selected seasons (Table 1). Only $35 \%$ of markets operated in winter, while just $61 \%$ and $9 \%$ of roadside stands operated in the autumn and winter, respectively. All supermarkets were open year-round.

Figures 1 and 2 illustrate availability patterns by outlet type for four leading fruits and four leading vegetables, showing the percentage of all sites at which the item was found (this accounts both for outlet closure and item availability). Because all of the supermarkets in the sample were open year-round, a small supermarket percentage indicates the lack of availability of the item. Availability results for all fruits and vegetables are presented in the online supplementary material, Supplemental Table 1.

The fruit and vegetable items exhibited three notable patterns in availability:

1. Seasonal in direct retail outlets. These items were available in supermarkets very often or always, but in direct retail outlets in selected seasons only. Examples include apples (Fig. 1(a)), cantaloupe (Fig. 1(c)), white potatoes (Fig. 2(a)), tomatoes (Fig. 2(b)) and sweet potatoes (Fig. 2(d)), as well as strawberries, blueberries, green beans, carrots, green cabbage, broccoli, cucumber, onion, zucchini, collard greens and romaine lettuce.

2. Seasonal in all outlets. These items were available in supermarkets and direct retail outlets in selected seasons only. Examples include peaches (Fig. 1(d)) and corn (Fig. 2(c)), as well as plums, watermelon and bunch spinach.

3. Less available year-round in direct retail outlets. These items exhibited little seasonality in supermarkets and were usually unavailable in direct retail outlets. Examples include oranges (Fig. 1(b)), as well as grapes, pears, pineapple, iceberg lettuce and asparagus.

Overall, even when outlets were open, farmers' markets and roadside stands had substantially lower availability for certain items in certain seasons.

\section{Question 2: Peak-season price competitiveness}

The second research question is whether, in the peak season, fruits and vegetables are less expensive at direct retail outlets. The peak-season results were the most

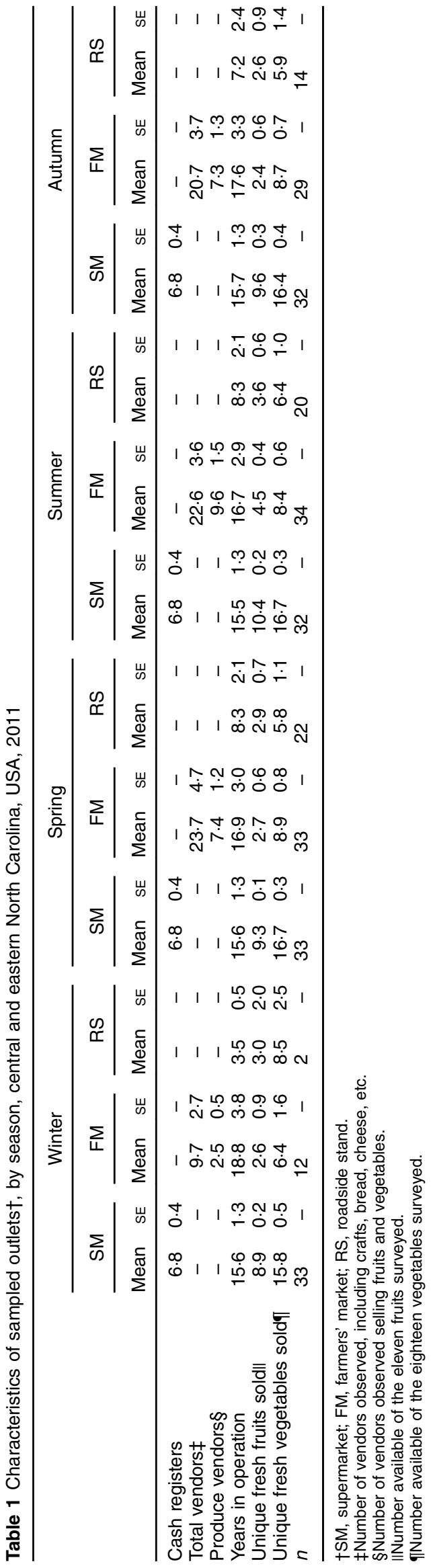




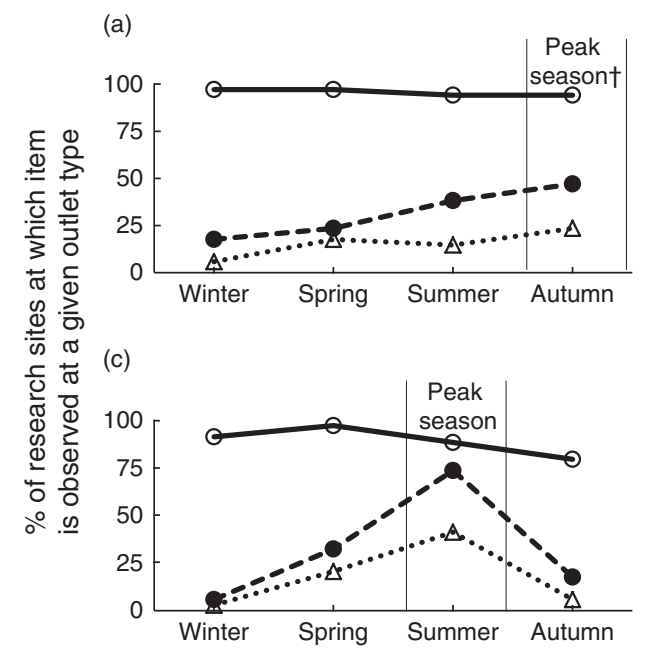

(b)
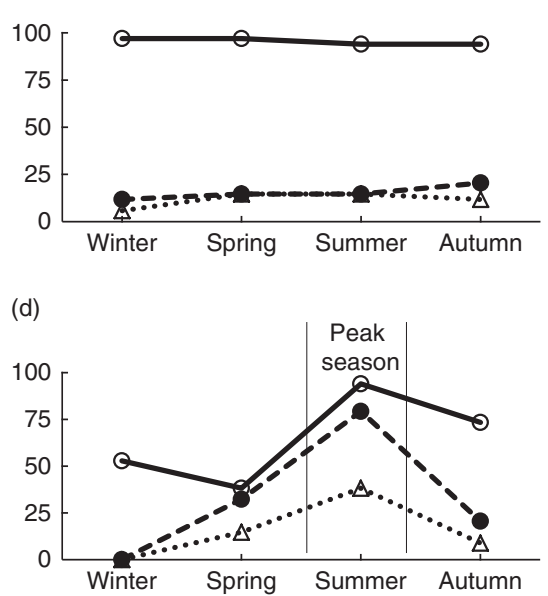

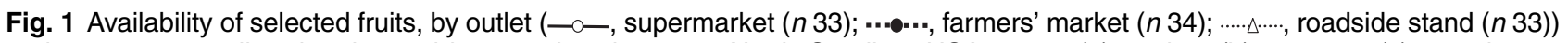
and season at retail outlets located in central and eastern North Carolina, USA, 2011: (a) apples; (b) oranges; (c) cantaloupe; (d) peaches. †Peak season refers to peak harvest season of the item in North Carolina
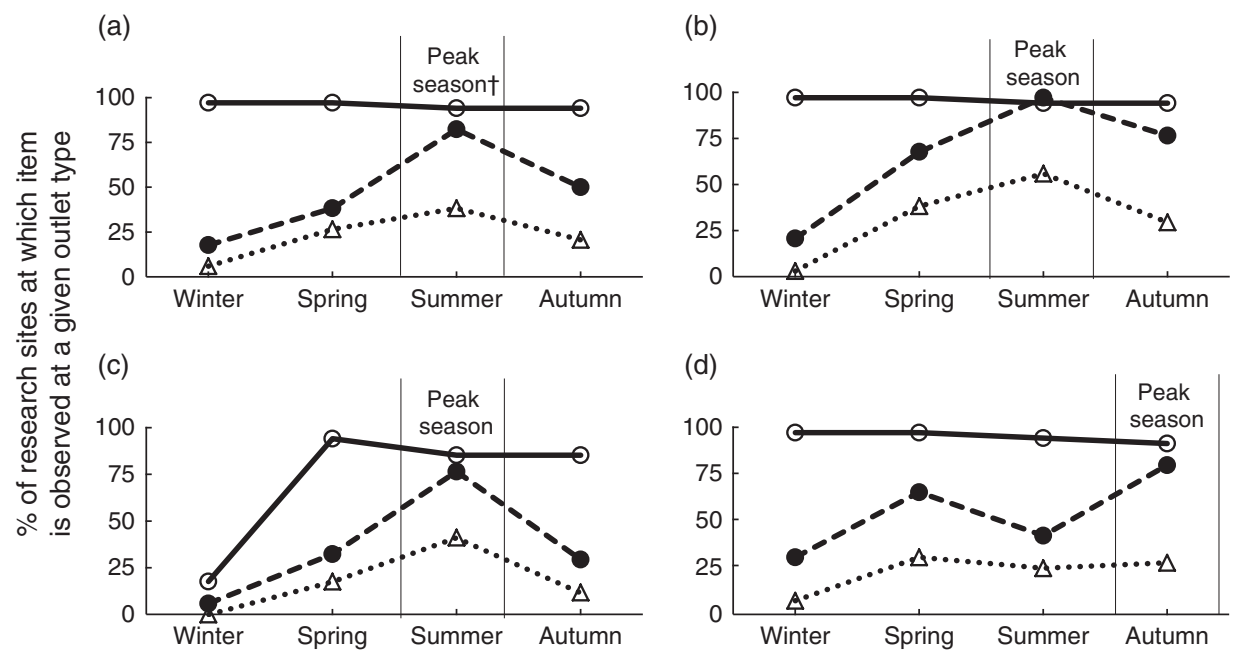

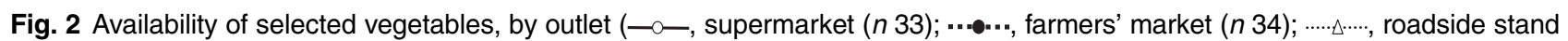
( $n$ 33)) and season at retail outlets located in central and eastern North Carolina, USA, 2011: (a) white potatoes; (b) tomatoes; (c) corn; (d) sweet potatoes. †Peak season refers to peak harvest season of the item in North Carolina

consistently well powered to detect significant price differences (see online supplementary material, Supplemental Table 2 for more complete item-season results and Supplemental Table 3 for mean prices). The answer to the second research question differed sharply across items (Table 2).

For one group of items, peak-season prices were significantly lower in direct retail outlets than supermarkets. Examples include cantaloupe prices in summer, which were $36.0 \%$ lower in roadside stands; summer squash prices in autumn, which were $30.0 \%$ lower in farmers' markets and $26.7 \%$ lower in road side stands; as well as tomatoes, plums and water melon (Table 2).
For a second group of items, by contrast, peak-season prices were significantly higher in direct retail outlets than in supermarkets. Examples include carrot prices in summer, which were $137.9 \%$ higher in farmers' markets; white potato prices in summer, which were $100 \cdot 0 \%$ higher in farmers' markets and $55.6 \%$ higher in roadside stands; as well as asparagus, onions and spinach (Table 2).

For a third group of items, there were no statistically significant differences in peak-season prices across outlet types. Such findings can arise because the outlet types actually were price competitive. For example, cucumbers were available at nearly all supermarkets and farmers' markets in the summer season, yet the price difference between the outlets was small $(2.4 \%)$ and statistically 
Table 2 Percentage by which mean fruit and vegetable prices at direct retail outlets exceed prices at supermarkets in the peak local harvest season, central and eastern North Carolina, USA, 2011†,‡

\begin{tabular}{|c|c|c|c|}
\hline & $\begin{array}{l}\text { Peak local harvest } \\
\text { season }\end{array}$ & $\begin{array}{c}\text { Farmers' } \\
\text { market }\end{array}$ & $\begin{array}{l}\text { Roadside } \\
\text { stand }\end{array}$ \\
\hline \multicolumn{4}{|l|}{ Fruit } \\
\hline Apples & Autumn & 3.3 & $-13 \cdot 3$ \\
\hline Blueberries & Summer & $2 \cdot 2$ & $-18 \cdot 7$ \\
\hline Cantaloupe & Summer & $-16 \cdot 0$ & $-36 \cdot 0^{\star \star}$ \\
\hline Grapes & Autumn & 7.9 & \\
\hline Oranges & $\mathrm{N} / \mathrm{A}$ & & \\
\hline Peaches & Summer & $56 \cdot 1$ & $-21 \cdot 1$ \\
\hline Pears & Autumn & & \\
\hline Pineapple & N/A & & \\
\hline Plums & Summer & $-24 \cdot 7^{\star}$ & \\
\hline Strawberry & Spring & $13 \cdot 2$ & $-23 \cdot 1$ \\
\hline Watermelon & Summer & $-42 \cdot 9^{\star}$ & $-28 \cdot 6^{*}$ \\
\hline \multicolumn{4}{|l|}{ Vegetables } \\
\hline Asparagus & Spring & $43 \cdot 8^{\star \star}$ & \\
\hline Broccoli & Spring & 21.9 & \\
\hline Cabbage & Autumn & $-5 \cdot 6$ & \\
\hline Carrots & $\begin{array}{l}\text { Summer } \\
\text { Winter }\end{array}$ & $137 \cdot 9^{\star \star}$ & \\
\hline \multirow[t]{2}{*}{ Collards } & Summer & 31.0 & \\
\hline & Autumn & $43 \cdot 2$ & \\
\hline Corn & Summer & $-33 \cdot 7$ & $-34 \cdot 6$ \\
\hline \multirow[t]{2}{*}{ Cucumber } & Summer & $-2 \cdot 4$ & -4.8 \\
\hline & Autumn & $-7 \cdot 1$ & \\
\hline \multirow{4}{*}{$\begin{array}{l}\text { Green beans } \\
\text { Iceberg lettuce } \\
\text { Mixed greens }\end{array}$} & Summer & $7 \cdot 1$ & -8.9 \\
\hline & Spring, autumn & & \\
\hline & Spring & 0.6 & \\
\hline & Autumn & -33.8 & \\
\hline Onions & Summer & $37 \cdot 8^{\star *}$ & \\
\hline Peas & Spring & $-31 \cdot 3$ & \\
\hline Potato (white) & Summer & $100 \cdot 0^{\star \star}$ & $55 \cdot 6^{*}$ \\
\hline \multirow{2}{*}{ Romaine lettuce } & Spring & 39.4 & \\
\hline & Autumn & $32 \cdot 4^{\star}$ & \\
\hline \multirow[t]{2}{*}{ Spinach } & Spring & $91 \cdot 2^{\star *}$ & \\
\hline & Autumn & & \\
\hline \multirow[t]{2}{*}{ Summer squash } & Summer & $-7 \cdot 0$ & $-16 \cdot 3$ \\
\hline & Autumn & $-30 \cdot 0^{\star *}$ & $-26 \cdot 7^{\star *}$ \\
\hline Sweet potato & Autumn & $3 \cdot 1$ & -21.9 \\
\hline \multirow{2}{*}{ Tomato } & Summer & -11.0 & $-30 \cdot 8^{\star}$ \\
\hline & Autumn & $-14 \cdot 6$ & $-20 \cdot 8$ \\
\hline
\end{tabular}

N/A, not applicable, item not produced in North Carolina.

†Price significantly different from that at supermarkets: ${ }^{*} P<0.05,{ }^{* \star} P<0.01$. $\ddagger$ Results reported if the sample size for an item-season-outlet combination was greater that or equal to eight. Supplemental Table 2 (see online supplementary material) presents expanded results for item-seasonoutlet combinations in which the sample size was greater than or equal to three.

insignificant (Table 2). Such findings also can arise simply because item availability was low, even in the peak season, so the comparison was not well powered, leading to statistically insignificant price differences (e.g. peaches, Fig. 1(d) and Table 2).

\section{Question 3: Price competitiveness in non-peak seasons}

The third research question is whether direct retail outlets and traditional supermarkets are price competitive in all seasons. Outside the local harvest season, availability of many items was limited in direct retail outlets. Nevertheless, several price comparison patterns are suggested by the well-powered results reported in Table 3 and the results based on smaller samples presented in the online supplementary material, Supplemental Table 2.

First, for many fruits, the lower prices observed at direct retail outlets were not confined to the peak harvest season. For example, cantaloupe prices were 19.6\% lower at farmers' markets in the spring, while watermelon prices were $40.7 \%$ lower at farmers' markets in the spring (Table 3). This pattern is even clearer when considering fruit items that were less frequently available: fruit prices were lower at one or both direct retail outlets for ten of the eleven fruits in the spring and summer and for eight of the eleven fruits in the autumn (see online supplementary material, Supplemental Table 2).

For a handful of vegetables, prices were significantly and substantially higher at direct retail outlets both in peak and out-of-peak seasons. For example, onions and white potatoes are more than twice the price at farmers' markets than at supermarkets in three seasons of the year (Table 3 and online supplementary material, Supplemental Table 2). Carrots, romaine lettuce and spinach also fit this pattern. For the remaining thirteen vegetable items, observed price differences across the year favoured direct retail outlets (Supplemental Table 2).

Finally, the magnitude of the price change from one season to the next varied more by item than by outlet type (see online supplementary material, Supplemental Table 4). In the case of carrots, iceberg and romaine lettuce, white and sweet potatoes, and tomatoes, supermarket prices varied little over the year and less than farmers' market prices for the item. For other items, however, such as blueberries, strawberries, watermelon and corn, prices fluctuated greatly between seasons at all outlets. No one outlet type consistently demonstrated larger price fluctuations.

\section{Discussion}

The present study examined produce availability and price patterns at farmers' markets, roadside stands and supermarkets in North Carolina in all four seasons. The seasonal availability patterns demonstrated marked differences in produce availability by outlet type. Of the three outlet types, only supermarkets made most items available yearround. Many of the sampled markets and roadside stands were not open in all seasons. Of the thirty-four farmers' markets and twenty-three roadside stands in our sample, just $35.3 \%$ and $8.7 \%$ respectively were open during the winter season. In the autumn, most farmers' markets were open but more than one-third of the roadside stands were closed. Furthermore, across seasons, direct retail outlets that were in operation sold about half the observed vegetables and just one-third of the observed fruits offered by supermarkets, on average.

These findings were expected, as direct retail outlets often purposefully market only that which is grown 
Table 3 Percentage by which mean fruit and vegetable prices at direct retail outlets exceed prices at supermarkets in non-peak seasons, central and eastern North Carolina, USA, 2011†,‡

\begin{tabular}{|c|c|c|c|c|}
\hline & Peak local harvest season & Non-peak season reported & Farmers' market & Roadside stand \\
\hline \multicolumn{5}{|l|}{ Fruit } \\
\hline Apples & Autumn & $\begin{array}{l}\text { Spring } \\
\text { Summer }\end{array}$ & $\begin{array}{c}-21.2^{*} \\
-2.9\end{array}$ & \\
\hline Cantaloupe & Summer & Spring & $-19 \cdot 6$ & \\
\hline Grapes & Autumn & Summer & 12.5 & \\
\hline Peaches & Summer & Spring & $-28 \cdot 3$ & \\
\hline Watermelon & Summer & Spring & $-40 \cdot 7$ & -3.5 \\
\hline \multicolumn{5}{|l|}{ Vegetables } \\
\hline Broccoli & Spring & Autumn & $9 \cdot 7$ & \\
\hline Cabbage & Summer, autumn & Spring & 5.9 & -5.9 \\
\hline Carrots & Summer, winter & Spring & $121 \cdot 4^{\star \star}$ & \\
\hline Corn & Summer & $\begin{array}{l}\text { Spring } \\
\text { Autumn }\end{array}$ & $\begin{array}{r}14 \cdot 8 \\
-20 \cdot 7\end{array}$ & \\
\hline Cucumber & Summer, autumn & Spring & $37 \cdot 8$ & -11.1 \\
\hline Green beans & Summer & $\begin{array}{l}\text { Spring } \\
\text { Autumn }\end{array}$ & $\begin{array}{l}-13.5 \\
-14.5\end{array}$ & \\
\hline Onions & Summer & $\begin{array}{l}\text { Spring } \\
\text { Autumn }\end{array}$ & $\begin{array}{l}72 \cdot 4^{\star \star} \\
37 \cdot 5^{\star \star}\end{array}$ & $\begin{array}{l}51 \cdot 7 \\
12.5\end{array}$ \\
\hline Potato & Summer & $\begin{array}{l}\text { Spring } \\
\text { Autumn }\end{array}$ & $\begin{array}{r}100 \cdot 0^{\star *} \\
96 \cdot 0^{\star *}\end{array}$ & $60 \cdot 0^{\star *}$ \\
\hline Sweet potato & Autumn & $\begin{array}{l}\text { Spring } \\
\text { Summer }\end{array}$ & $\begin{array}{r}3.2 \\
-6.5\end{array}$ & $\begin{array}{l}-11.3 \\
-11.3\end{array}$ \\
\hline Tomato & Summer, autumn & Spring & 11.7 & -4.3 \\
\hline
\end{tabular}

†Price significantly different from that at supermarkets: ${ }^{\star} P<0.05,{ }^{\star \star} P<0.01$.

$\ddagger$ Results reported if the sample size for an item-season-outlet combination was greater than or equal to eight. Supplemental Table 2 (see online supplementary material) presents expanded results for item-season-outlet combinations in which the sample size was greater than or equal to three.

nearby. Such markets, for example, choose not to carry strawberries in the autumn or pineapples in any season. One important benefit of this local specificity is that, in many cases, the direct retail outlets visited carry specialty vegetables neither observed for the present study nor widely sold in supermarkets. This provision of specialty items or heirloom produce varieties enables the consumer to discover new flavours and add variety to his diet. Even so, the availability findings highlight the continued importance of traditional supermarkets in promoting year-round access and intake for the most-consumed produce items.

Supermarkets were not always the leader on price. It was expected that fruits and vegetables would be cheapest at direct retail outlets during the local harvest season, as supply peaked. Estimates showed this to be true in several, but not all, cases. Some items, such as watermelon and cantaloupe, were substantially cheaper at direct retail outlets in the peak season, while estimates for other items such as apples and cucumbers showed little price difference despite the large number of observations. These peak-season results, in which direct retail prices offered were similar to or lower than those in supermarkets, corroborate previous research that demonstrated the competitiveness of farmers' markets in the summer season $^{(17,18)}$.

The present study builds on the previous research by comparing prices not only in the peak harvest season, but also throughout the year. These non-peak results were based on a smaller number of observed prices and thus offer less statistical power than peak-season comparisons. The results, although often statistically insignificant, nevertheless suggested several noteworthy patterns. First, contingent on item availability, direct retail outlets seem to provide most fruit items at lower prices than supermarkets across multiple seasons. Some of the observed fruit price differences were of large magnitude. For example, blueberries were $39 \cdot 5 \%$ and $50 \cdot 2 \%$ less expensive at farmers' markets and roadside stands, respectively, than at supermarkets in the spring. Second, non-peak vegetable price comparisons sometimes favoured direct outlets and other times favoured supermarkets. Aside from the few items for which the price was substantially and consistently lower at supermarkets year-round (white potatoes, carrots, onions, romaine lettuce), the magnitude of vegetable price differences in the non-peak seasons was in many cases less than $20 \%$.

The finding that direct retail competitiveness was not confined to the peak harvest season is not surprising in light of the results regarding magnitude of seasonal price change. It was hypothesized that price change from one season to the next would be greatest at direct retail outlets, explaining, in part, their peak-season competitiveness. Yet, there were few significant differences between outlet types in the magnitude of seasonal price shifts. Substantial change in price from one season to the next seemed as much due to the type of fruit or vegetable as to the retail outlet type. The price of fruits and vegetables that can be stored for long periods, such as apples, pears, carrots and white and sweet potatoes, fluctuated less across seasons 
than the price of those that are best consumed soon after harvest such as berries, watermelon and tomatoes.

Future studies with improved power may be able to confirm the significance of observed non-peak season price differences which sometimes favoured direct retail (as in the case of roadside stand vegetables and direct retail fruits) and sometimes did not (farmers' market vegetables). If they do so, they would bolster these results which indicate that direct retail outlets in central and eastern North Carolina are price competitive with traditional supermarkets not just in the local harvest season, but year-round. All three outlets could help consumers minimize the cost of meeting fruit and vegetable recommendations.

Previous studies have documented seasonal fluctuation in both the type and quantity of fruit and vegetable intake $^{(32,35-38)}$. Research also suggests that seasonal fluctuation in consumption may have negative health consequences ${ }^{(39-41)}$. To the extent that price affects fruit and vegetable intake, this ability of burgeoning local food outlets to offer competitive prices in multiple seasons underscores their potential usefulness as a tool to boost the consistency of produce intake across the year, assuming challenges of limited item availability can be addressed.

For consumers with access to local food retail outlets, maintaining produce consumption across all seasons while minimizing cost may require legwork to understand price patterns in the particular locality. Just as no one outlet type consistently provided lower prices in a season, no outlet type offered larger seasonal swings in price across all items. The data presented here suggest that generalizations such as 'local produce is cheaper in the harvest season' paint an inaccurate picture of the food price environment.

These results are subject to several limitations. First, prices may reflect real, unmeasured differences in produce quality. Such differences may explain some of the counterintuitive results, such as the higher price for farmers' market peaches during the local harvest season. Second, premiums at local food outlets may result in part from a greater availability of organic items for sale at these outlets than at supermarkets. However, controlling for organic production did not result in consistently lower prices at local outlets (results not shown). Third, these results remain specific to central and eastern North Carolina. This local specificity may be desirable in research on produce prices, however, as seasonal price patterns have been shown to vary by region ${ }^{(37)}$.

Due to the need to cover a large research area with limited resources, prices were observed just once per season at each outlet. Given intra-season price variation noted at farmers' markets in a non-peer reviewed study as well as weekly specials at supermarkets, the single visit likely captured the lowest price of an item offered during the month at some outlets while missing it at others ${ }^{(20)}$. However, the enumerators collected data continually over each season's four-week survey period. Because the region has fairly uniform weather and growing conditions, and because twenty-three of the thirtythree supermarkets in the sample belonged to one of two retail chains, the sum of the observations likely captured the intra-season variation in prices and specials. Thus, although the lowest price per season may not have been captured for each outlet, the results remain good estimates of the central tendency of seasonal prices for produce items sold in the region, allowing useful comparisons by outlet type.

\section{Conclusion}

A greater number of the fruits and vegetables most commonly consumed by Americans were available at North Carolina supermarkets, in each season of the year, than at direct retail outlets. Produce availability at direct retail outlets was further limited in the winter season by closure of more than half of the studied farmers' markets and more than three-quarters of studied roadside stands. Yet, for many but not all fruits and vegetables, those farmers' markets and roadside stands in operation offered prices that were competitive, on average, with those at traditional supermarkets in central and eastern North Carolina yearround. Consumers could utilize direct retail outlets, when open, as well as supermarkets to meet fruit and vegetable recommendations at minimal cost.

\section{Acknowledgements}

Financial support: This material is based upon work supported by the National Science Foundation Graduate Research Fellowship (grant number DGF-0806676). The funder had no role in the design, analysis or writing of this article. Conflict of interest: None. Authorship: All authors contributed to formulation of the research questions and study design. N.V. implemented the study. N.V. led the analyses and writing; P.W. collaborated on both. All authors helped to interpret findings and review drafts of the manuscript. Ethics of human subject participation: This study was determined exempt from review by the Tufts University Institutional Review Board at Medford.

\section{Supplementary material}

To view supplementary material for this article, please visit http://dx.doi.org/10.1017/S1368980015000981

\section{References}

1. World Cancer Research Fund/American Institute for Cancer Research (2007) Food, Nutrition, Physical Activity, and the Prevention of Cancer: A Global Perspective. Washington, DC: AICR 
2. US Department of Agriculture \& US Department of Health and Human Services (2010) Dietary Guidelines for Americans, 2010, 7th ed. Washington, DC: US Government Printing Office.

3. Dauchet L, Amouyel P, Hercberg S et al. (2006) Fruit and vegetable consumption and coronary heart disease: a metaanalysis of cohort studies. J Nutr 136, 2588-2593.

4. 2010 Dietary Guidelines Advisory Committee (2010) Report of the Dietary Guidelines Advisory Committee on the Dietary Guidelines for Americans, 2010. Alexandria, VA: USDA Center for Nutrition Policy and Promotion.

5. Centers for Disease Control and Prevention (2009) State Indicator Report on Fruits and Vegetables, 2009. http://www.cdc.gov/nutrition/downloads/StateIndicatorReport 2009.pdf (accessed December 2010).

6. Larson NI, Story MT \& Nelson MC (2009) Neighborhood environments: disparities in access to healthy foods in the US. Am J Prev Med 36, 74-81.

7. Michimi A \& Wimberly M (2010) Associations of supermarket accessibility with obesity and fruit and vegetable consumption in the coterminous United States. Int J Health Geogr 9, 49.

8. Bodor N, Rose D, Farley T et al. (2008) Neighbourhood fruit and vegetable availability and consumption: the role of small food stores in an urban environment. Public Health Nutr 11, 413-420.

9. Cassady D, Jetter K \& Culp J (2007) Is price a barrier to eating more fruits and vegetables for low-income families? J Am Diet Assoc 107, 1909-1915.

10. Drewnowski A, Darmon N \& Briend A (2004) Replacing fats and sweets with vegetables and fruits - a question of cost. Am J Public Health 94, 1555-1559.

11. Dong D \& Lin B-H (2009) Fruit and Vegetable Consumption by Low-income Americans: Would a Price Reduction Make a Difference? Economic Research Report no. 70. Washington, DC: USDA, Economic Research Service.

12. Pollard J, Kirk S \& Cade J (2002) Factors affecting food choice in relation to fruit and vegetable intake: a review. Nutr Res Rev 15, 373-387.

13. Powell L, Zhao Z \& Wang Y (2009) Food prices and fruit and vegetable consumption among young American adults. Health Place 15, 1064-1070.

14. Yeh M-C, Ickes S, Lowenstein L et al. (2008) Understanding barriers and facilitators of fruit and vegetable consumption among a diverse multi-ethnic population in the USA. Health Promot Int 23, 42-51.

15. Caldwell E, Kobayashi MM \& DuBow W (2009) Perceived access to fruits and vegetables associated with increased consumption. Public Health Nutr 12, 1743-1750.

16. Larsen K \& Gilliland J (2009) A farmers' market in a food desert: evaluating impacts on the price and availability of healthy food. Health Place 15, 158-1162.

17. Sommer R, Wing M \& Aitkens S (1980) Price savings to consumers at farmers' markets. J Consum Aff 14, 452-462.

18. McGuirt J, Jilcott S, Liu H et al. (2011) Produce price savings for consumers at farmers' markets compared to supermarkets in North Carolina. J Hunger Environ Nutr 6, 86-98.

19. Pirog R \& McCann N (2009) Is Local Food More Expensive? A Consumer Price Perspective on Local and Non-local Foods Purchased in Iowa. Ames, IA: Leopold Center for Sustainable Agriculture, Iowa State University.

20. Claro J (2011) Vermont Farmers' Markets and Grocery Stores: A Price Comparison. Richmond, VT: Northeast Organic Farming Association of Vermont.

21. Low S, Adalja A, Beaulieu E et al. (2015) Trends in US Local and Regional Food Systems. Report to Congress. Administrative Publication no. AP-068. Washington, DC: USDA, Economic Research Service.
22. Tronstad R (1995) Importance of melon type, size, grade, container, and season in determining melon prices. J Agric Resour Econ 20, 32-48.

23. Parker D, Zilberman D \& Moulton K (1991) How quality relates to price in California fresh peaches. Calif Agric $\mathbf{4 5}$, issue $2,14-16$.

24. Riley HE (1961) Some aspects of seasonality in the consumer price index. J Am Stat Assoc 56, 27-35.

25. Schotzko RT \& Granatstein D. A Brief Look at the Washington Apple Industry: Past and Present SES 04-05. Wenatchee, WA: Washington State University.

26. McLaughlin E (2004) The dynamics of fresh fruit and vegetable pricing in the supermarket channel. Prev Med 39, Suppl. 2, S81-S87.

27. Andreatta S \& Wickliffe W (2002) Managing farmer and consumer expectations: a study of a North Carolina farmers market. Hum Organ 61, 167-176.

28. NY State Consumer Protection Board (n.d.) Stretch your dollar effort: Grocery shopping tips. http://www.nyscon sumer.gov/pdf/educating/shopping/on_your_syde_grocery_ shopping_tips.pdf (accessed July 2010).

29. CT Department of Consumer Protection (2010) Saving Money at the Grocery Store. http://www.ct.gov/dcp/cwp/ view.asp? $\mathrm{a}=1629 \& \mathrm{q}=421268$ (accessed July 2010).

30. Valpiani N (2013) Price competitiveness of fruits and vegetables at local food retail outlets in all seasons of the year. PhD Thesis, Tufts University.

31. Bowman S, Friday J \& Moshfegh A (2008) MyPyramid Equivalents Database, 2.0 for USDA Survey Foods, 2002004. Beltsville, MD: USDA, Agricultural Research Service; available at http://www.ars.usda.gov/ba/bhnrc/fsrg.

32. Wilkins J (2002) Consumer perceptions of seasonal and local foods: a study in a US community. Ecol Food Nutr $\mathbf{4 1}$, 415-439.

33. Centers for Disease Control and Prevention, National Center for Health Statistics (2007-2010) National Health and Nutrition Examination Survey Data. http://www.cdc.gov/ nchs/nhanes/search/datapage.aspx?Component=Dietary\& CycleBeginYear $=2009$

34. US Department of Agriculture, Agricultural Research Service (2005) USDA National Nutrient Database for Standard Reference, Release 18. Nutrient Data Laboratory Home Page. http://www.ars.usda.gov/ba/bhnrc/ndl.

35. Locke E, Coronado GD, Thompson B et al. (2009) Seasonal variation in fruit and vegetable consumption in a rural agricultural community. J Am Diet Assoc 109, 45-51.

36. Johnson A, McFetridge M \& Durham C (2005) Store-level retail fruit demand: lessons from omitted variables. J Food Distrib Res 36, 91-94.

37. Todd J, Leibtag E \& Penberthy C (2011) Geographic Differences in the Relative Price of Healthy Foods. Economic Information Bulletein no. EIB-78. Washington, DC: USDA, Economic Research Service.

38. Amanatidis S, Mackerras D \& Simpson JM (2001) Comparison of two frequency questionnaires for quantifying fruit and vegetable intake. Public Health Nutr 4, 233-239.

39. Smolková B, Dušinská M, Rašlová K et al. (2004) Seasonal changes in markers of oxidative damage to lipids and DNA; correlations with seasonal variation in diet. Mutat Res 551, 135-144.

40. Ziegler R, Wilcox H, Mason T et al. (1987) Seasonal variation in intake of carotenoids and vegetables and fruits among white men in New Jersey. Am J Clin Nutr 45, 107-114.

41. Cox B, Whichelow M \& Prevost T (2000) Seasonal consumption of salad vegetables and fresh fruit in relation to the development of cardiovascular disease and cancer. Public Health Nutr 3, 19-29. 